\title{
Optimization of Water Resource Management Using Chooser Option Contracts under Uncertainty
}

\author{
Zhichao Gao ${ }^{1,2}$, Hong Zhang2, Minghu Ha1,2* \\ ${ }^{1}$ School of Management, Hebei University, Baoding, China \\ ${ }^{2}$ School of Science, Hebei University of Engineering, Handan, China \\ Email: zhchgao@hebeu.edu.cn, zhanghong@hebeu.edu.cn, ‘mhha@hbu.edu.cn
}

How to cite this paper: Gao, Z.C., Zhang, H. and Ha, M.H. (2018) Optimization of Water Resource Management Using Chooser Option Contracts under Uncertainty. American Journal of Industrial and Business Management, 8, 1308-1326.

https://doi.org/10.4236/ajibm.2018.85089

Received: April 25, 2018

Accepted: May 21, 2018

Published: May 24, 2018

Copyright ( $\odot 2018$ by authors and Scientific Research Publishing Inc. This work is licensed under the Creative Commons Attribution International License (CC BY 4.0). http://creativecommons.org/licenses/by/4.0/

\begin{abstract}
Optimization of water resource management is very important to reduce water shortage risk and increase economic benefit. Water option can be used as a flexible instrument in water resource management. In this study, chooser options are designed for water managers to buy additional water in drought periods and sell redundant water in wet periods. To make optimal decisions under uncertainties including probability distributions and intervals, an inexact two-stage mixed-integer programming (ITSMIP) model is applied. To illustrate the role of chooser options in water resource management, a case study is presented. Factors which influence the willingness of buying the chooser options are analyzed and the optimal water allocation plans are also provided. The results demonstrate that chooser options can help water managers mitigate the impact of water shortage and increase utilization efficiency of water resource greatly.
\end{abstract}

\section{Keywords}

Inexact Optimization, Two-Stage Programming, Chooser Option, Water Allocation

\section{Introduction}

Water shortage is becoming increasingly severe due to climate change, ever growing population, industrialization and environmental pollution. To ensure the sustainable development of economy and society, various water conservancy projects, such as interbasin water transfer systems and reservoirs, are constructed. Against this background, domestic water managers face more and more difficulties 
in water allocation under conditions of uncertainty. If the promised water allocation targets are not realized, water shortage can result in more economic penalties [1].

For the purpose of optimal allocation of water, innovative economic and financial instruments are necessary. Numerous authors have proposed innovative instruments which increase the efficient use of water. Calatrava [2] found that exchanging water in market can help users to reduce risk exposure. Bjornlund [3] found that sophisticated water market instruments, such as options and futures, can be adopted in Australia with the improving of economic fundamentals. Burke et al. [4] developed an approach for water banking by integrating hydrologic and economic aspects. They concluded that an interproject banking scheme might be appropriate for increasing the efficient use of water.

Among these instruments, water options have been increasingly used within some water markets [5] [6] [7] [8] [9]. By using water options, water managers can make decisions until obtaining more information about water levels. As the holders of the options, water managers have the right to buy or sell some water at a certain price accordingly [8]. In this way, water options can greatly help water managers reduce water shortage risk and improve economic benefits [10].

In the process of water resource management, uncertainty and complexity that come from social, economic and environmental factors should be taken into account. To deal with the uncertainties, mathematical approaches are widely used. For example, Yamout et al. [11] examined the performance of five water resource allocation models when uncertainties in the models were represented by normal probability distributions. Esogbue and Liu [12] applied fuzzy criterion decision process to model the multi-reservoir operation problems. Stedinger et al. [13] defined a reservoir release policy by using a stochastic dynamic programming model and calculated the expected benefits from future operation by using the best forecast of the current period's inflow. Esogbue [14] first applied fuzzy sets theory to the optimal flood control problem and proposed a two-level optimization model for planning decisions. Huang and Loucks [15] proposed a hybrid model of inexact optimization and two-stage stochastic programming model in which uncertainties are expressed as not only probability distributions but also intervals. They applied the model to a case study of water resource management and provided useful decision support for water managers.

In this study, an water option named chooser option is defined for managing water resource in a region that is subject to a high degree of uncertainty. We present an inexact two-stage mixed-integer programming (ITSMIP) model that determines the optimal chooser option purchase, the optimal option execution and the optimal water allocation program. The model is applied to a case study and the effect of chooser options on water resource decision making and factors which influence the willingness of buying the chooser options under uncertainty is analysed.

The rest of the paper is arranged as follows. In Section 2, chooser options for water resource management and an inexact two-stage mixed-integer programming 
(ITSMIP) model are presented to analyze water resource management problems involving chooser options. In Section 3, a hypothetical case study is provided to illustrate the effect of the chooser options. In Section 4, a conclusion is drawn.

\section{Methodology}

\subsection{Chooser Options for Water Resource Management}

Options are derivative instruments giving the holder the right but not the obligation to buy or sell something at predetermined prices, subject to certain conditions depending on the option types. For acquiring an option, the option holder must pay a premium to the option seller [16]. Exotic options are options which are more complex than standard put and call options. With the growing demand for cost-reduction and special customer needs, more and more exotic options were created and became popular [17].

According to particular markets or clients, several classes of exotic options are developed. For example, Asian options are one of the most popular path-dependent options. They based on the average underlying prices, indices or rates during some pre-set period of time [17]. Exchange options are options that give the right to exchange one underlying asset for another. They are the basic type of multi-asset options. Besides the two classes of options mentioned above, other popular exotic options include compound options, nonlinear payoff options, contingent premium options, chooser options and so on [17].

Water options are exotic options that are designed for empowering water managers to buy or sell some water at certain prices under some conditions [5] [18]. By using call options in water resource management, water managers can make purchase decisions and lock in the water prices until the water availability and requirements became clear [8]. Therefore, water options are flexible, cost-minimising and risk-reducing instruments for managing limited water resource [10].

A standard chooser option allows the holder to choose the option to be either a put or a call at some prespecified future time before the option's expiration time [17] [19] [20]. In this paper, we will design chooser options for water managers to hedge water shortage risk during drought and sell redundant water during the high flow periods for more system net benefit. With chooser options, water managers can buy additional water at the expiration date at an agreed price if the accumulated inflows fall below a predetermined threshold. And on the other side, they can sell redundant water at the expiration date at an agreed price if the inflows are higher than needed. The option holder could decide how much water to buy or sell without exceeding the optioned volume.

This decision-making process is a two-stage programme [8] [9]. At first, the water manager should decide the water supply target for every user and whether to buy the chooser option under the uncertain circumstances that water demand and accumulated inflows are unknown. Second, when the uncertainties are resolved and the conditions of the option are met, the water manager would 
make decisions on the chooser option and water supplies for every users [10].

\subsection{Optimisation Model}

Two-stage stochastic programming have been widely used in water resource management [21]. For example, Wang and Adams [22] used periodic Markov processes to describe reservoir inflows and established a two-stage stochastic optimization for real-time reservoir operations in consideration of hydrologic uncertainty and seasonality. Huang and Loucks [23] proposed an inexact two-stage stochastic programming (ITSP) model, which included not only stochastic uncertainties but also ambiguous information expressed as intervals, for allocating water resources under uncertainty. Other related papers are [24] [25] [26] [27].

Suppose that a water manager is responsible for water resource management in a region. There are three competing users in the region: a municipality, an industrial concern and an agricultural sector. The water manager should determine water supply targets for every user. And the users make their business plans according to their water supply targets. If the accumulated inflows are low, the water delivered will fall below the determined targets and the system net benefit will be reduced. If the accumulated inflows are high, the water delivered will meet the needs of the three users' requirments and the redundant water can be sold to other regions through interbasin water transfer systems to increase utilization rate of water. In the following, to realise the above water management goal, chooser options are designed for the water manager and a two-stage optimization model including the possibility of buying a chooser option is formulated. The proposed problem is a two stage stochastic mixed-integer programming (TSMIP) model as follows:

$$
\max f=\sum_{i=1}^{u} N B_{i} \times T_{i}+E\left[S_{Q} \times P_{1}-O P \times\left(A_{Q}+B_{Q}\right) \times R-W_{Q} \times P_{2}-\sum_{i=1}^{u} C_{i} \times D_{i Q}\right],
$$

subject to:

Water availability:

$$
\sum_{i=1}^{u}\left(T_{i}-D_{i Q}\right) \leq Q+W_{Q}-S_{Q}, \forall i
$$

Maximum target of water allocation:

$$
T_{i \max } \geq T_{i} \geq D_{i Q} \geq 0, \forall i,
$$

Minimum target of water allocation:

$$
T_{i}-D_{i Q} \geq T_{i \min }, \forall i
$$

Water option contract:

$$
\begin{cases}W_{Q} \leq A_{Q} \times R, & \text { if } Q \leq M_{A}, \\ W_{Q}=0, & \text { if } Q \geq M_{A}\end{cases}
$$




$$
\begin{cases}S_{Q} \leq B_{Q} \times R, & \text { if } Q \geq M_{B} \\ S_{Q}=0, & \text { if } Q \leq M_{B}\end{cases}
$$

nonnegative constraints:

$$
\begin{gathered}
W_{Q} \geq 0, \\
S_{Q} \geq 0,
\end{gathered}
$$

where

f. total system net benefit (\$);

$C_{i}$ : loss per unit of water to user $i$ when the promised water do not delivered $\left(C_{i} \geq N B_{i}\right)\left(\$ / \mathrm{m}^{3}\right)$;

$D_{i Q}$ : shortage volume of user $i$ when present flow is $Q\left(\mathrm{~m}^{3}\right)$;

$E[\cdot]$ : expected value of random variables;

i: $i=1$ refers to the municipality, $i=2$ refers to the industrial concern and $i=3$ refers to the agricultural sector;

$u$ : number of water users;

$N B_{i}$ : net benefit per unit of water to user $i\left(\$ / \mathrm{m}^{3}\right)$;

$Q$ : random variable represents water inflow $\left(\mathrm{m}^{3}\right)$;

$T_{i}$ : water allocation target promised to user $i\left(\mathrm{~m}^{3}\right)$;

$T_{i \max }$ : maximum target of water allocation $\left(\mathrm{m}^{3}\right)$;

$T_{i \text { min }}:$ minimum target of water allocation $\left(\mathrm{m}^{3}\right)$;

$O P$ : premium of chooser option (\$);

$A_{Q}$ : optioned volume $\mathrm{A}$, maximum amount of water provided by exercising the chooser option when present inflow is $Q\left(\mathrm{~m}^{3}\right)$;

$B_{Q}$ : optioned volume $\mathrm{B}$, maximum amount of water that can be sold by exercising the chooser option when present inflow is $Q\left(\mathrm{~m}^{3}\right)$;

$R$ : binary variable, 1 when the water manager decides to buy the chooser option, 0 otherwise;

$W_{Q}$ : exercised volume of purchases when the option is exercised and the present inflow is $Q\left(\mathrm{~m}^{3}\right)$;

$S_{Q}$ : exercised volume of of sales when the option is exercised and the present inflow is $Q\left(\mathrm{~m}^{3}\right)$;

$P$. exercise price (\$);

$M_{A}$ : preestablished value, the chooser option can be exercised if the inflow is smaller than it.

$M_{B}$ : preestablished value, the chooser option can be exercised if the inflow is larger than it.

To solve this model, suppose $Q$ take discrete values $q_{j}$ with probabilities $p_{j}$ for $j=1,2, \cdots, n$, we have [23]:

$$
\begin{aligned}
& E\left[S_{Q} \times P_{1}-O P \times\left(A_{Q}+B_{Q}\right) \times R-W_{Q} \times P_{2}-\sum_{i=1}^{u} C_{i} \times D_{i Q}\right] \\
& =\sum_{j=1}^{n} S_{Q j} \times P_{1} \times p_{j}-\sum_{j=1}^{n} O P \times\left(A_{j}+B_{j}\right) \times R \times p_{j}-\sum_{j=1}^{n} W_{Q j} \times P_{2} \times p_{j}-\sum_{i=1}^{u} C_{i}\left(\sum_{j=1}^{n} D_{i j} p_{j}\right)
\end{aligned}
$$


where $A_{j}$ is the maximum amount of water purchased, and $B_{j}$ is the maximum amount of water sold by exercising the chooser option when present inflow is $q_{j}$ with probability $p_{p} W_{Q j}$ is the amount of purchases when the chooser option is exercised and the present inflow is $q_{j}$ with probability $p_{p} S_{Q j}$ is the amount of sales when the chooser option is exercised and the present inflow is $q_{j}$ with probability $p_{p} \quad D_{i j}$ is the shortage volume of user $i$ when the water allocation target $T_{i}$ is not met and the present inflow is $q_{j}$ with probability $p_{j}$. Then, we can reformulate the foregoing problem as:

$$
\begin{aligned}
\max f= & \sum_{i=1}^{u} N B_{i} \times T_{i}+\left(\sum_{j=1}^{n} S_{Q j} \times P_{1} \times p_{j}-\sum_{j=1}^{n} O P \times\left(A_{j}+B_{j}\right) \times R \times p_{j}\right. \\
& \left.-\sum_{j=1}^{n} W_{Q j} \times P_{2} \times p_{j}-\sum_{i=1}^{u} C_{i}\left(\sum_{j=1}^{n} D_{i j} p_{j}\right)\right),
\end{aligned}
$$

subject to:

$$
\begin{gathered}
\sum_{i=1}^{u}\left(T_{i}-D_{i j}\right) \leq q_{j}+W_{Q j}-S_{Q j}, \forall j, \\
T_{i \max } \geq T_{i} \geq D_{i j} \geq 0, \forall i, j, \\
T_{i}-D_{i j} \geq T_{i \min }, \forall i, j, \\
\left\{\begin{array}{ll}
W_{Q j} \leq A_{j} \times R, & \text { if } q_{j} \leq M_{A}, \\
W_{Q j}=0, & \text { if } q_{j} \geq M_{A},
\end{array} \forall j .\right. \\
\left\{\begin{array}{ll}
S_{Q j} \leq B_{j} \times R, & \text { if } q_{j} \geq M_{B}, \\
S_{Q j}=0, & \text { if } q_{j} \leq M_{B},
\end{array} \forall j .\right.
\end{gathered}
$$

nonnegative constraints:

$$
W_{Q j}, S_{Q j} \geq 0, \forall j
$$

The above TSMIP model can effectively reflect stochastic uncertainties in water availability. It can help decide whether to buy the option contract and set proper water allocation targets in the first stage. However, there are more uncertainties that should be considered in the model. For example, the economic parameters $\left(C_{i}\right.$ and $\left.N B_{i}\right)$ may not be described by deterministic values or random variable but intervals. Moreover, the water manager often feels difficult to make deterministic water allocation decisions $\left(T_{i}\right.$ and $\left.D_{i j}\right)$, but would prefer to give ranges of the decision variables [23]. To reflect such uncertainties, Huang and Loucks [23] introduced an inexact two-stage stochastic programming (ITSP) model. This leads to an inexact two-stage stochastic mixed integer programming (ITSMIP) model as follows:

$$
\begin{aligned}
\max f^{ \pm}= & \sum_{i=1}^{u} N B_{i}^{ \pm} \times T_{i}^{ \pm}+\left(\sum_{j=1}^{n} S_{Q j}^{ \pm} \times P_{1} \times p_{j}-\sum_{j=1}^{n} O P \times\left(A_{j}+B_{j}\right) \times R \times p_{j}\right. \\
& \left.-\sum_{j=1}^{n} W_{Q j}^{ \pm} \times P_{2} \times p_{j}-\sum_{i=1}^{u} C_{i}^{ \pm}\left(\sum_{j=1}^{n} D_{i j}^{ \pm} p_{j}\right)\right),
\end{aligned}
$$

subject to: 


$$
\begin{gathered}
\sum_{i=1}^{u}\left(T_{i}^{ \pm}-D_{i j}^{ \pm}\right) \leq q_{j}^{ \pm}+W_{Q j}^{ \pm}-S_{Q j}^{ \pm}, \forall j, \\
T_{i \max }^{ \pm} \geq T_{i}^{ \pm} \geq D_{i j}^{ \pm} \geq 0, \forall i, j, \\
T_{i}^{ \pm}-D_{i j}^{ \pm} \geq T_{i \min }^{ \pm}, \forall i, j, \\
\begin{cases}W_{Q j}^{ \pm} \leq A_{j} \times R, & \text { if } q_{j}^{ \pm} \leq M_{A}, \forall j . \\
W_{Q j}^{ \pm}=0, & \text { if } q_{j}^{ \pm} \geq M_{A},\end{cases} \\
\left\{\begin{array}{ll}
S_{Q j}^{ \pm} \leq B_{j} \times R, & \text { if } q_{j}^{ \pm} \geq M_{B}, \\
S_{Q j}^{ \pm}=0, & \text { if } q_{j}^{ \pm} \leq M_{B},
\end{array},\right.
\end{gathered}
$$

nonnegative constraints:

$$
\begin{gathered}
W_{Q j}^{ \pm}, S_{Q j}^{ \pm} \geq 0, \forall j . \\
R=0,1 .
\end{gathered}
$$

In this paper, we will follow the method proposed by Huang and Loucks [23]. When $T_{i}^{ \pm}$is given, the ITSMIP model can be transformed into two deterministic submodels as follows:

Step 1: A submodel corresponding to $f^{+}$is desired since the expected system net benefit needs to be maximized. Let $T_{i}^{+}\left(T_{i}^{-}\right)$be the maximum target of water allocation (minimum target of water allocation), $T_{i}^{ \pm}=T_{i}^{-}+y_{i}\left(T_{i}^{+}-T_{i}^{-}\right)$, where $y_{i} \in[0,1]$, the submodel for $f^{+}$can be formulated as follows:

$$
\begin{aligned}
\max f^{+}= & \sum_{i=1}^{u} N B_{i}^{+} \times\left(T_{i}^{-}+y_{i}\left(T_{i}^{+}-T_{i}^{-}\right)\right) \\
& +\left\{\sum_{j=1}^{n} S_{Q j}^{+} \times P_{1} \times p_{j}-\sum_{j=1}^{n} O P \times\left(A_{j}+B_{j}\right) \times R \times p_{j}\right. \\
& \left.-\sum_{j=1}^{n} W_{Q j}^{-} \times P_{2} \times p_{j}-\sum_{i=1}^{u} C_{i}^{-}\left(\sum_{j=1}^{n} D_{i j}^{-} p_{j}\right)\right\},
\end{aligned}
$$

subject to:

$$
\begin{gathered}
\sum_{i=1}^{u}\left(T_{i}^{-}+y_{i}\left(T_{i}^{+}-T_{i}^{-}\right)-D_{i j}^{-}\right) \leq q_{j}^{+}+W_{Q j}^{-}-S_{Q j}^{+}, \forall i, j, \\
T_{i \max }^{+} \geq T_{i}^{-}+y_{i}\left(T_{i}^{+}-T_{i}^{-}\right) \geq D_{i j}^{-} \geq 0, \forall i, j, \\
T_{i}^{-}+y_{i}\left(T_{i}^{+}-T_{i}^{-}\right)-D_{i j}^{-} \geq T_{i \min }^{+}, \forall i, j, \\
\left\{\begin{array}{ll}
W_{Q j}^{-} \leq A_{j} \times R, & \text { if } q_{j}^{ \pm} \leq M_{A}, \\
W_{Q j}^{-}=0, & \text { if } q_{j}^{ \pm} \geq M_{A},
\end{array} \forall j .\right. \\
\left\{\begin{array}{ll}
S_{Q j}^{+} \leq B_{j} \times R, & \text { if } q_{j}^{ \pm} \leq M_{B}, \\
S_{Q j}^{+}=0, & \text { if } q_{j}^{ \pm} \geq M_{B},
\end{array}, \forall j .\right.
\end{gathered}
$$

nonnegative constraints:

$$
\begin{gathered}
W_{Q j}^{-}, S_{Q j}^{+} \geq 0, \forall j, \\
0 \leq y_{i} \leq 1,
\end{gathered}
$$




$$
R=0,1
$$

where $R, W_{Q j}^{-}, S_{Q j}^{+}, D_{i j}^{-}$and $y_{i}$ are decision variables.

Step 2: Let $f_{\text {opt }}^{+}, R_{\text {opt }}, W_{\text {jopt }}^{-}, S_{\text {jopt }}^{+}, D_{\text {ijopt }}^{-}$and $y_{\text {iopt }}$ be the solutions in Step 1. Then the optimal decision on whether to buy the water option contract is based on $R_{o p t}$, and the optimized water-allocation targets are as follows:

$$
T_{\text {iopt }}^{ \pm}=T_{i}^{-}+y_{\text {iopt }}\left(T_{i}^{+}-T_{i}^{-}\right), \forall i .
$$

Step 3: The submodel for $f^{-}$can be formulated as follows:

$$
\begin{aligned}
\max f^{-}= & \sum_{i=1}^{u} N B_{i}^{-} \times\left(T_{i}^{-}+y_{\text {iopt }}\left(T_{i}^{+}-T_{i}^{-}\right)\right) \\
& +\left\{\sum_{j=1}^{n} S_{Q_{j}}^{-} \times P_{1} \times p_{j}-\sum_{j=1}^{n} O P \times\left(A_{j}+B_{j}\right) \times R_{o p t} \times p_{j}\right. \\
& \left.-\sum_{j=1}^{n} W_{Q j}^{+} \times P_{2} \times p_{j}-\sum_{i=1}^{u} C_{i}^{+}\left(\sum_{j=1}^{n} D_{i j}^{+} p_{j}\right)\right\},
\end{aligned}
$$

subject to:

$$
\begin{gathered}
\sum_{i=1}^{u}\left(T_{i}^{-}+y_{\text {iopt }}\left(T_{i}^{+}-T_{i}^{-}\right)-D_{i j}^{+}\right) \leq q_{j}^{+}+W_{Q j}^{+}-S_{Q j}^{-}, \forall j, \\
T_{i \max }^{-} \geq T_{i}^{-}+y_{\text {iopt }}\left(T_{i}^{+}-T_{i}^{-}\right) \geq D_{i j}^{+} \geq 0, \forall i, j, \\
T_{i}^{-}+y_{\text {iopt }}\left(T_{i}^{+}-T_{i}^{-}\right)-D_{i j}^{+} \geq T_{i \min }^{-}, \forall i, j, \\
\left\{\begin{array}{ll}
W_{Q j}^{+} \leq A_{j} \times R_{\text {opt }}, & \text { if } q_{j}^{ \pm} \leq M_{A}, \\
W_{Q j}^{+}=0, & \text { if } q_{j}^{ \pm} \geq M_{A},
\end{array}, \forall j .\right. \\
\left\{\begin{array}{ll}
S_{Q j}^{-} \leq B_{j} \times R, & \text { if } q_{j}^{ \pm} \leq M_{B}, \\
S_{Q j}^{-}=0, & \text { if } q_{j}^{ \pm} \geq M_{B},
\end{array},\right.
\end{gathered}
$$

nonnegative constraints:

$$
W_{Q j}^{+}, S_{Q j}^{-} \geq 0, \forall j
$$

where $W_{Q j}^{+}, S_{Q j}^{-}$and $D_{i j}^{+}$are decision variables.

Let $f_{\text {opt }}^{-}, W_{\text {jopt }}^{+}, S_{\text {jopt }}^{-}$and $D_{\text {ijopt }}^{+}$be the solutions of the model above, we obtain

$$
\begin{gathered}
f_{\text {opt }}^{ \pm}=\left[f_{\text {opt }}^{-}, f_{\text {opt }}^{+}\right] ; \\
D_{\text {ijopt }}^{ \pm}=\left[D_{\text {ijopt }}^{-}, D_{i j o p t}^{+}\right], \forall i, j ; \\
W_{j o p t}^{ \pm}=\left[W_{\text {jopt }}^{-}, W_{\text {jopt }}^{+}\right], \forall j ; \\
S_{\text {jopt }}^{ \pm}=\left[S_{\text {jopt }}^{-}, S_{\text {jopt }}^{+}\right], \forall j .
\end{gathered}
$$

\section{Case Study}

\subsection{Case Description}

To illustrate the applicability of the proposed method, a case study is provided in the following. Suppose that a water manager is responsible for managing water 
resource in a region. There are three users: a municipality, an industrial concern and an agricultural sector. The users need to know in advance the water allocation targets so as to arrange their activities accordingly. However, inflows of the region is uncertain. During drought periods, the promised water may not be delivered, the users will suffer losses due to the lack of water. On the other hand, when the inflows are high, water demands can be met completely and it is possible to have surplus water. In this case, the water manager can sell the surplus water for more profit through interbasin water transfer systems.

In order to achieve the objects above, chooser options are provided to the water manager as flexible, risk control and cost-minimising tools. Chooser options have several parameters to be set. The optioned water volume $(A / B)$ is the maximum volume that the water manager can buy or sell. The option premium $(O P)$ is the cost paid to the option seller for the chooser option. The strike price $(P)$ is the price at which the water manager can buy or sell the optioned water. The trigger $M_{A}$ and $M_{B}$ are thresholds that if the water inflows are lower than $M_{A}$, the water manager can buy the optioned water at most; if the water inflows are higher than $M_{B}$, the water manager can sell the optioned water at most.

Figure 1 is the decision-making process of chooser options. In the first stage, the water manager should decide whether to buy the chooser option under uncertainty. In the second stage, if the inflow is lower than trigger $M_{A}$, the water manager choose the chooser option to be a call option; if the inflow is higher than trigger $M_{B}$, the water manager choose the chooser option to be a put option. Meanwhile the exercised volume is decided based on the demands and other parameters.

In consideration of uncertainties in the system, related water inflows and economic data are obtained from a number of representative cases [23] [28]. The data reflects the uncertainties in water inflows as probability and the parameters such as benefits, penalties are expressed as intervals. Table 1 provides the water resource data. The inflows are divided into seven levels: Very-low (V-L), Low (L), Low-medium (L-M), Medium (M), Medium-high (M-H), High (H) and

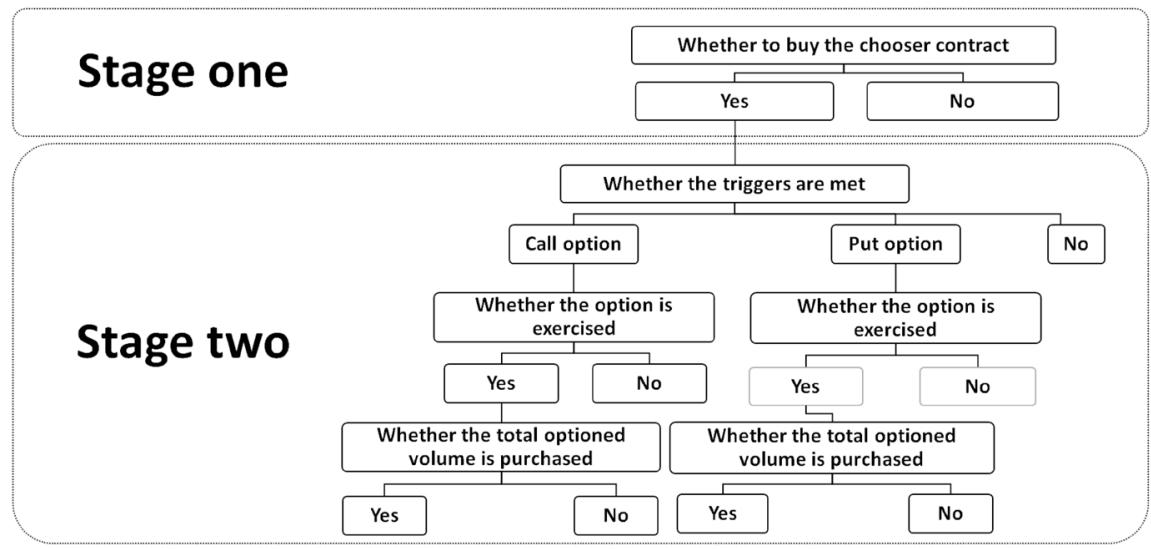

Figure 1. Decision tree of the option contract. 
Table 1. Stream inflow distribution.

\begin{tabular}{ccc}
\hline Inflow level & Probability & Water inflows $\left(10^{6} \mathrm{~m}^{3}\right)$ \\
\hline Very-low (V-L) & 0.08 & {$[3.80,5.20]$} \\
Low (L) & 0.12 & {$[5.50,6.50]$} \\
Low-medium (L-M) & 0.16 & {$[6.90,8.20]$} \\
Medium (M) & 0.25 & {$[8.50,9.80]$} \\
Medium-high (M-H) & 0.15 & {$[10.0,11.5]$} \\
High (H) & 0.14 & {$[11.5,12.9]$} \\
Very-high (V-H) & 0.1 & {$[13.2,14.5]$} \\
\hline
\end{tabular}

Very-high (V-H). The amount of water inflows and relative appearance probability for every level are also showed in Table 1 . Table 2 provides the water demands and related economic data [23] [28]. $T_{i \min }$ is the minimum water volume that must be allocated to meet the basic demands of user $i, T_{i \max }$ is the largest quantity of water that can be used by user $i, N B_{i}$ is the net benefit per unit of water to user $i, C_{i}$ the loss per unit of water to user $i$ when the promised water do not delivered $\left(C_{i} \geq N B_{i}\right)$.

As the purpose is to maximize the expected value of system net benefits, the concerned problems include: 1) whether the chooser option are attractive to the water manager; 2) With the chooser option, how to set the water allocation targets in the first stage; 3 ) whether the chooser option would be exercised; 4) how to allocate water to users in the second stage; 5) What is the impact of chooser options on system net benefit. In the following, the ITSMIP model is applied to dealing with these problems.

\subsection{Decision Result Analysis of the First Stage}

First of all, the water manager should decide whether to buy the chooser option for sale. Different exercise price levels, premium levels, optioned volumes and triggers would strongly affect the decision-making.

To find out the relationships between these parameters and the optimal $R, 225$ different cases are studied according to different settings of these parameters. The solutions are showed in Table 3 and Table 4. In Table 3, the premiums are percentages of the water price, the trigger A is $L-M$, trigger B is $H$; In Table 4, the volume $A$ is 7 , the volume $B$ is 3 . In 72.4 per cent of all the 225 cases, the water manager would buy the chooser options.

Figure 2 and Figure 3 are the frequency charts of Table 3. It is indicated that decreasing trend of buying the chooser options with the rise of the optioned volume $A, B$ and the water price. This is because with the optioned volume and increasing, the costs of buying the chooser options also increase. For example, when $M_{A}=L-M, M_{B}=H$ and $P=40$, the frequency of buying the chooser options decreases from 9 when $A=5$ to 7 when $A=7$ and further decreases to 6 when $A=9$; when $M_{A}=L-M, M_{B}=H$ and $A=7$, the 


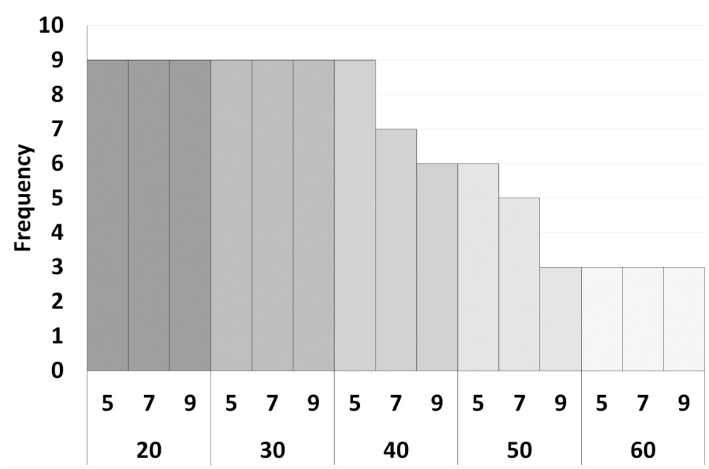

Figuer 2. Frequency of buying chooser options for each optioned volume $A$.

Table 2. Water target demands and related economic data.

\begin{tabular}{llccc}
\hline & \multicolumn{3}{c}{ Users } \\
\cline { 3 - 5 } & Municipal & Industrial & Agricaltural \\
\hline Maximum allowable allocation, $T_{i \max }\left(10^{6} \mathrm{~m}^{3}\right)$ & 4 & 5.5 & 6.5 \\
Minimum allowable allocation, $T_{i \min }\left(10^{6} \mathrm{~m}^{3}\right)$ & 1.5 & 1 & 1 \\
Net benefit when water demand is satisfied, $N B_{i}^{ \pm}$ & $\left(\$ / \mathrm{m}^{3}\right)$ & {$[90,100]$} & {$[45,55]$} & {$[25,35]$} \\
Penalty when water is not delivered, $C_{i}^{ \pm}\left(\$ / \mathrm{m}^{3}\right)$ & {$[125,135]$} & {$[70,80]$} & {$[45,55]$} \\
\hline
\end{tabular}

Table 3. The optimal decisions whether to buy the chooser option.

\begin{tabular}{|c|c|c|c|c|c|c|c|c|c|c|}
\hline \multirow{3}{*}{ Price } & \multirow{3}{*}{ Premium } & \multicolumn{9}{|c|}{ Volume } \\
\hline & & \multicolumn{3}{|c|}{5} & \multicolumn{3}{|c|}{7} & \multicolumn{3}{|c|}{9} \\
\hline & & 3 & 4 & 5 & 3 & 4 & 5 & 3 & 4 & 5 \\
\hline \multirow[t]{3}{*}{20} & 0.05 & 1 & 1 & 1 & 1 & 1 & 1 & 1 & 1 & 1 \\
\hline & 0.10 & 1 & 1 & 1 & 1 & 1 & 1 & 1 & 1 & 1 \\
\hline & 0.15 & 1 & 1 & 1 & 1 & 1 & 1 & 1 & 1 & 1 \\
\hline \multirow[t]{3}{*}{30} & 0.05 & 1 & 1 & 1 & 1 & 1 & 1 & 1 & 1 & 1 \\
\hline & 0.10 & 1 & 1 & 1 & 1 & 1 & 1 & 1 & 1 & 1 \\
\hline & 0.15 & 1 & 1 & 1 & 1 & 1 & 1 & 1 & 1 & 1 \\
\hline \multirow[t]{3}{*}{40} & 0.05 & 1 & 1 & 1 & 1 & 1 & 1 & 1 & 1 & 1 \\
\hline & 0.10 & 1 & 1 & 1 & 1 & 1 & 1 & 1 & 1 & 1 \\
\hline & 0.15 & 1 & 1 & 1 & 1 & 0 & 0 & 0 & 0 & 0 \\
\hline \multirow[t]{3}{*}{50} & 0.05 & 1 & 1 & 1 & 1 & 1 & 1 & 1 & 1 & 1 \\
\hline & 0.10 & 1 & 1 & 1 & 1 & 1 & 0 & 0 & 0 & 0 \\
\hline & 0.15 & 0 & 0 & 0 & 0 & 0 & 0 & 0 & 0 & 0 \\
\hline \multirow[t]{3}{*}{60} & 0.05 & 1 & 1 & 1 & 1 & 1 & 1 & 1 & 1 & 1 \\
\hline & 0.10 & 0 & 0 & 0 & 0 & 0 & 0 & 0 & 0 & 0 \\
\hline & 0.15 & 0 & 0 & 0 & 0 & 0 & 0 & 0 & 0 & 0 \\
\hline
\end{tabular}

1: Buy the option contract. 0: Do not buy the option contract. 


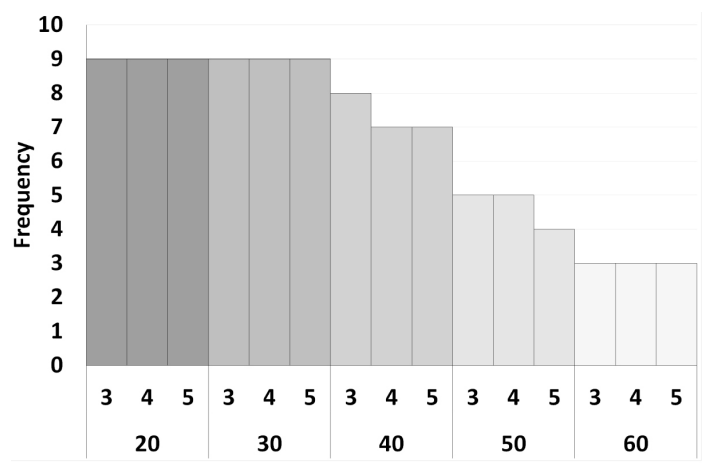

Figuer 3. Frequency of buying chooser options for each optioned volume $B$.

Table 4. The optimal decisions whether to buy the chooser option.

\begin{tabular}{|c|c|c|c|c|c|c|c|}
\hline \multirow{3}{*}{ Price } & \multirow{3}{*}{ Premium } & \multicolumn{6}{|c|}{ Trigger } \\
\hline & & \multicolumn{2}{|c|}{ M } & \multicolumn{2}{|c|}{ L-M } & \multicolumn{2}{|c|}{$\mathrm{L}$} \\
\hline & & $\mathrm{H}$ & V-H & $\mathrm{H}$ & $\mathrm{V}-\mathrm{H}$ & $\mathrm{H}$ & $\mathrm{V}-\mathrm{H}$ \\
\hline \multirow[t]{3}{*}{20} & 0.05 & 1 & 1 & 1 & 1 & 1 & 1 \\
\hline & 0.10 & 1 & 1 & 1 & 1 & 1 & 1 \\
\hline & 0.15 & 1 & 1 & 1 & 1 & 1 & 1 \\
\hline \multirow[t]{3}{*}{30} & 0.05 & 1 & 1 & 1 & 1 & 1 & 1 \\
\hline & 0.10 & 1 & 1 & 1 & 1 & 1 & 1 \\
\hline & 0.15 & 1 & 1 & 1 & 1 & 1 & 1 \\
\hline \multirow[t]{3}{*}{40} & 0.05 & 1 & 1 & 1 & 1 & 1 & 1 \\
\hline & 0.10 & 1 & 1 & 1 & 1 & 1 & 1 \\
\hline & 0.15 & 1 & 1 & 1 & 0 & 0 & 0 \\
\hline \multirow[t]{3}{*}{50} & 0.05 & 1 & 1 & 1 & 1 & 1 & 1 \\
\hline & 0.10 & 1 & 0 & 1 & 0 & 0 & 0 \\
\hline & 0.15 & 0 & 0 & 0 & 0 & 0 & 0 \\
\hline \multirow[t]{3}{*}{60} & 0.05 & 1 & 1 & 1 & 1 & 1 & 0 \\
\hline & 0.10 & 0 & 0 & 0 & 0 & 0 & 0 \\
\hline & 0.15 & 0 & 0 & 0 & 0 & 0 & 0 \\
\hline
\end{tabular}

1: Buy the option contract. 0: Do not buy the option contract.

frequency of buying the chooser options decreases from 9 when $P=20$ to 6 when $P=40$ and further decreases to 3 when $P=60$. Figure 4 and Figure 5 are the frequency charts of Table 4. It is indicated that decreasing trend of buying the chooser options with relaxing restrictions on the triggers and the rise of the water price. This is because with the optioned volume and increasing, the costs of buying the chooser options also increase. For example, when $A=7$, $B=3$ and $P=40$, the frequency of buying the chooser options decreases from 6 when $M_{A}=M$ to 5 when $M_{A}=L-M$ and further decreases to 4 when $M_{A}=L$; when when $A=7, B=3$ and $M_{B}=H$, the frequency of buying the 
chooser options decreases from 9 when $P=20$ to 8 when $P=40$ and further decreases to 3 when $P=60$.

Figure 6 shows the trends of the allocation targets when the exercise price increases from 5 to 100 while maintaining all other parameters unchanged. In all cases, the water manager would buy the chooser options. By comparison, the

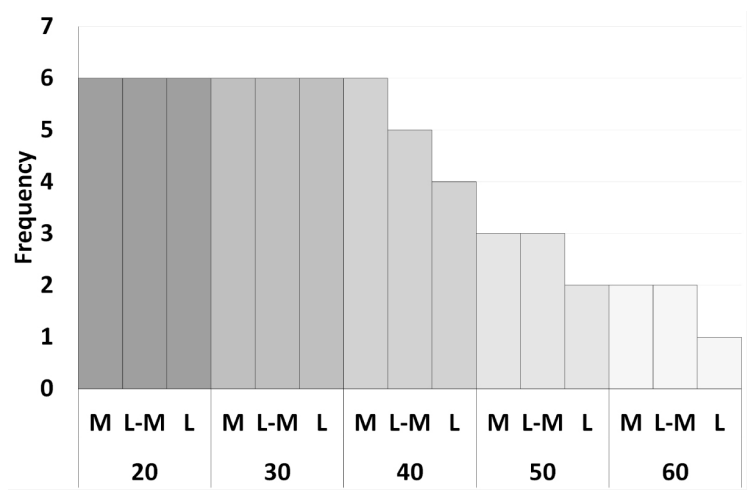

Figuer 4. Frequency of buying chooser options for each trigger $M_{A}$.

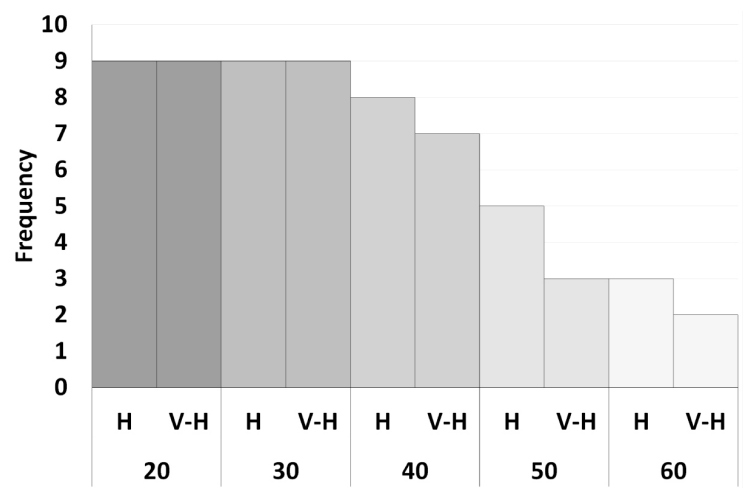

Figuer 5. Frequency of buying chooser options for each trigger $M_{B}$

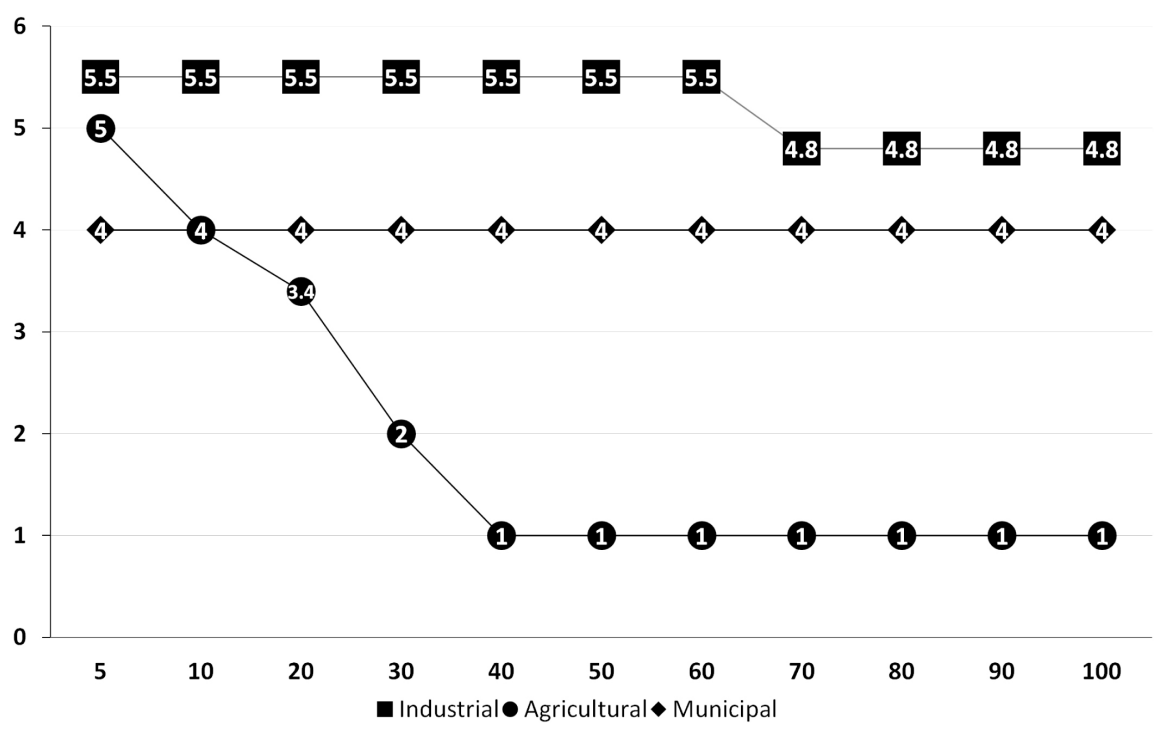

Figure 6. Water allocation targets. 
water allocation targets without chooser options are 4.0 for the municipality, 5.5 for industrial concern and 3.4 for agricultural sector. It is obviously the municipality and industrial concern are set targets higher than the agricultural sector because of their higher net benefits. We can also find that when the exercise prices are 5 and 10, the targets for the agricultural sector are significantly improved to 5 and 4 respectively. But with the exercise price rising from 20 to 100, the targets for the agricultural sector decline from 3.4 to 1, and the targets for the industrial concern decline from 5.5 to 4.8 too. This is because the water manager prefers to sell water by exercising the chooser option rather than allocate water to the users when the exercise prices are high.

\subsection{Decision Result Analysis of the Second Stage}

In this stage, all the uncertainties are eliminated. The 225 cases show that the chooser options would always be exercised if they are bought in the first stage and the triggers are satisfied in the second stage. The water manager should decide how much water to buy or sell by exercising the chooser option and the water allocation for each user.

Figure 7 and Figure 8 present the upper and lower bounds of the exercised volume. The exercise prices increase from 5 to 100 with the other parameters invariant $\left(M_{A}=L-M, M_{B}=H, A=7, B=5\right)$. The probability that the chooser option is a call option is $36 \%$ when $M_{A}=L-M$ and the probability that the chooser option is a put option is $24 \%$ when $M_{B}=H$. When the exercise price is low, the optioned volume is almost all exercised to meet the users' water demand. But with the exercise price rising, the optimal exercised volume is becoming less and less. For example when the water price is 10 , the exercised volume $A$ is $[5.3,6.6]$ when the water inflow is $L-M$ and the exercised volume $B$ is $[0,1]$ when the water inflow is $H$; when the water price is 50, the exercised volume $A$ is $[4,5]$ when the water inflow is $L$ and the exercised volume $B$ is $[2.7,4]$ when the water inflow is $H$; when the water price is 90 , the exercised volume $A$ is $[0.8,2.2]$ when the water inflow is $V-L$ and the exercised volume $B$ is 5 when the water inflow is $H$.

The optimal water allocation results varies with different parameters of chooser option. Higher trigger and higher optioned volume would lead to a higher allocation. As shown in Table 5, when the inflows are low $(V-L, L$ or $L-M)$, because water resource can be supplemented by using the chooser options, water shortage is reduced. But when the inflows are high ( $H$ or $V-H$ ), water shortage of agricultural sector becomes serious because part of the water is sold for more benefits.

Figure 9 shows the increased percentage of system net benefit by using chooser options. The system net benefit is increased obviously in all cases and the lower bound is increased even more. But the system net benefit is falling because the cost of buying water is increasingly high with the exercise price rising. However, For example, when the exercise price is 10, the system net 


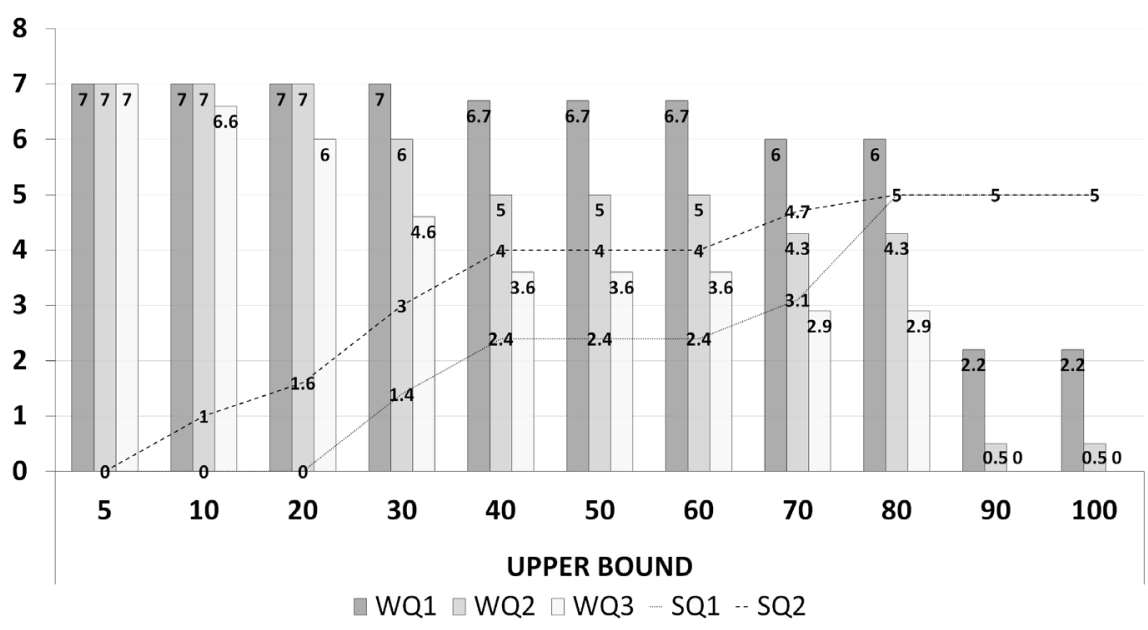

Figuer 7. Upper bound of the optimized exercised volume.

Table 5. Water shortage with and without option $\operatorname{contract}\left(M_{A}=L-M, M_{B}=H\right.$, $O P=0.05, A=7, B=5$ ).

\begin{tabular}{|c|c|c|c|c|c|c|c|c|c|}
\hline \multirow{2}{*}{$\begin{array}{l}\text { Water } \\
\text { level }\end{array}$} & \multirow{2}{*}{ User } & \multicolumn{7}{|c|}{ With option contract } & \multirow{2}{*}{$\begin{array}{c}\text { Without } \\
\text { option }\end{array}$} \\
\hline & & $P=10$ & $P=20$ & $P=30$ & $P=40$ & $P=50$ & $P=60$ & $P=70$ & \\
\hline \multirow[t]{3}{*}{ V-L } & Municipal & 0 & 0 & 0 & 0 & 0 & 0 & 0 & {$[0.8,2.2]$} \\
\hline & Industrial & 0 & 0 & 0 & 0 & 0 & 0 & {$[0,3.8]$} & 4.5 \\
\hline & Agricultural & 2.7 & 2.7 & {$[0,2.7]$} & 0 & 0 & 0 & 0 & 2.4 \\
\hline \multirow[t]{3}{*}{$\mathrm{L}$} & Municipal & 0 & 0 & 0 & 0 & 0 & 0 & 0 & {$[0.0,0.5]$} \\
\hline & Industrial & 0 & 0 & 0 & 0 & 0 & 0 & {$[0,3.3]$} & {$[4.0,4.5]$} \\
\hline & Agricultural & {$[0,1]$} & {$[0,0.4]$} & 0 & 0 & 0 & 0 & 0 & 2.4 \\
\hline \multirow[t]{3}{*}{ L-M } & Municipal & 0 & 0 & 0 & 0 & 0 & 0 & 0 & 0 \\
\hline & Industrial & 0 & 0 & 0 & 0 & 0 & 0 & {$[0,1.6]$} & {$[2.3,3.6]$} \\
\hline & Agricultural & 0 & 0 & 0 & 0 & 0 & 0 & 0 & 2.4 \\
\hline \multirow[t]{3}{*}{ M } & Municipal & 0 & 0 & 0 & 0 & 0 & 0 & 0 & 0 \\
\hline & Industrial & {$[0.7,2]$} & {$[0.7,2]$} & {$[0.7,2]$} & {$[0.7,2]$} & {$[0.7,2]$} & {$[0.7,2]$} & {$[0,1.3]$} & {$[0.7,2.0]$} \\
\hline & Agricultural & 3 & 2.4 & 1 & 0 & 0 & 0 & 0 & 2.4 \\
\hline \multirow[t]{3}{*}{$\mathrm{M}-\mathrm{H}$} & Municipal & 0 & 0 & 0 & 0 & 0 & 0 & 0 & 0 \\
\hline & Industrial & {$[0,0.5]$} & {$[0,0.5]$} & {$[0,0.5]$} & {$[0,0.5]$} & {$[0,0.5]$} & {$[0,0.5]$} & 0 & {$[0.0,0.5]$} \\
\hline & Agricultural & {$[2,3]$} & {$[1.4,2.4]$} & {$[0,1]$} & 0 & 0 & 0 & 0 & {$[1.4,2.4]$} \\
\hline \multirow[t]{3}{*}{$\mathrm{H}$} & Municipal & 0 & 0 & 0 & 0 & 0 & 0 & 0 & 0 \\
\hline & Industrial & 0 & 0 & 0 & 0 & 0 & 0 & 0 & 0 \\
\hline & Agricultural & {$[0.6,2]$} & {$[0,1.4]$} & 0 & 0 & 0 & 0 & 0 & {$[0.0,1.4]$} \\
\hline \multirow[t]{3}{*}{ V-H } & Municipal & 0 & 0 & 0 & 0 & 0 & 0 & 0 & 0 \\
\hline & Industrial & 0 & 0 & 0 & 0 & 0 & 0 & 0 & 0 \\
\hline & Agricultural & {$[0,0.3]$} & 0 & 0 & 0 & 0 & 0 & 0 & 0 \\
\hline
\end{tabular}




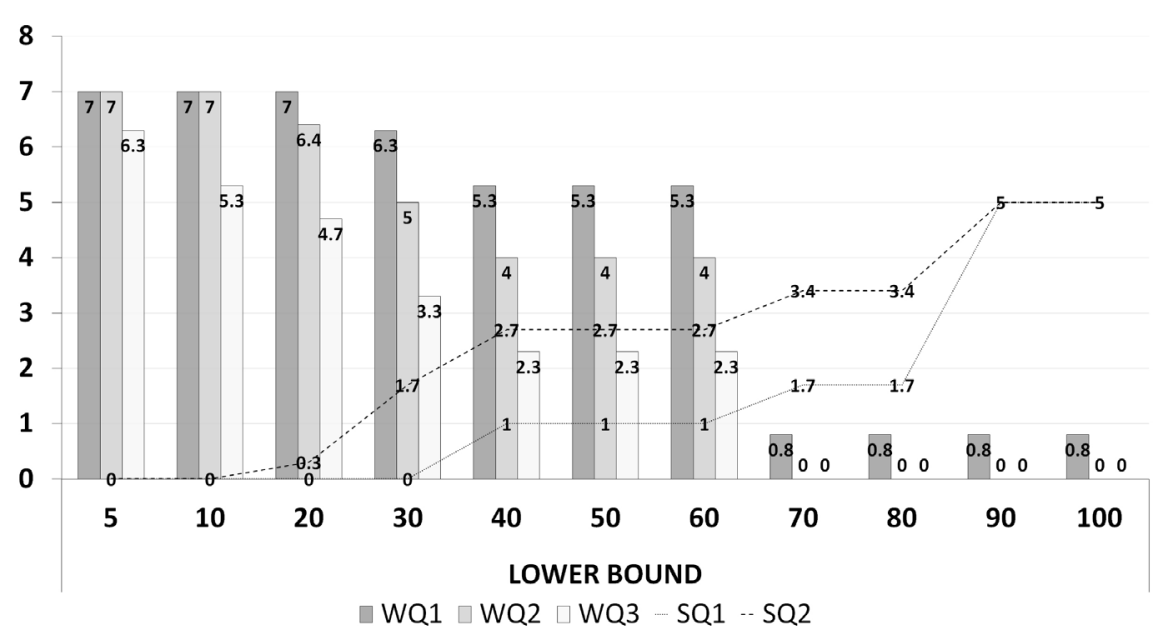

Figuer 8. Lower bound of the optimized exercised volume.

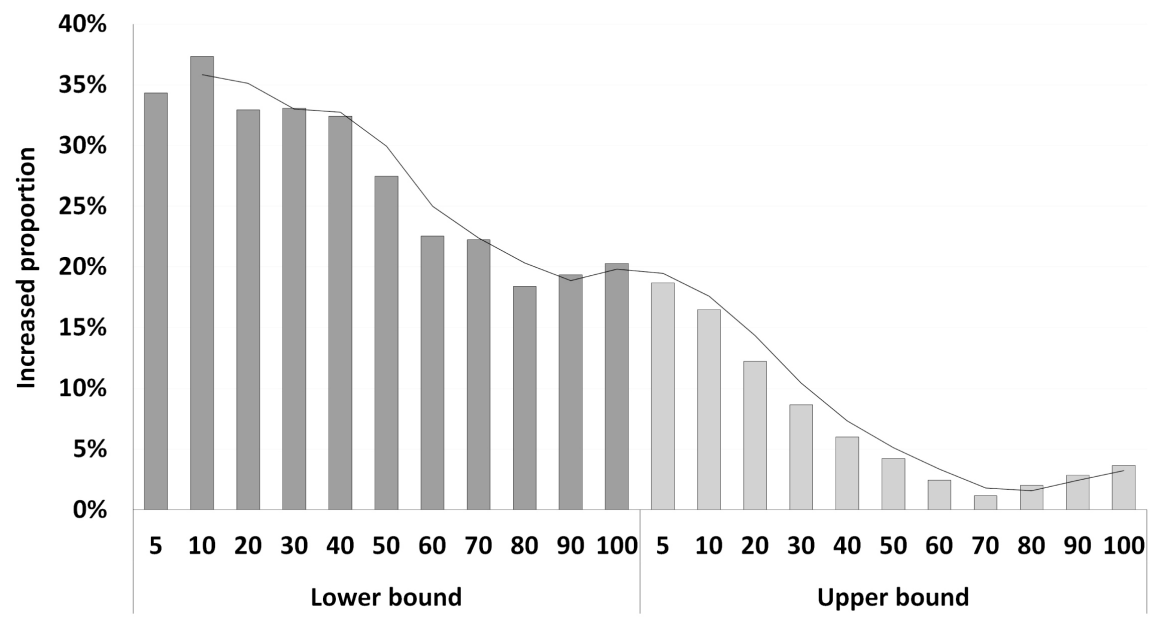

Figure 9. Increased proportion of system net benefit.

benefit is increased by $[16.5 \%, 37.3 \%]$ compared to without chooser option. But when the exercise price rises to 80 , the system net benefit is only increased by $[2.0 \%, 18.4 \%]$ compared to without chooser option.

\section{Conclusion}

Water users have to make decisions under the condition that water inflow is uncertain. If the water inflow level is low, they will suffer loss because of water shortage. But if the water inflow is higher than needed, redundant water runs to waste. To solve this problem, chooser options are designed for water managers. This type of option allows water manager to choose the option to be either a put or a call at some prespecified future time depending on the information about water inflow and requirements. Exercise price, optioned volume, option premium and exercise trigger are the parameters of chooser options. They can affect the willingness of water managers to buy chooser options. For analysing the decision making process, an inexact two-stage mixed-integer programming (ITSMIP) 
model has been applied to a case study when chooser options are proposed. More than 225 chooser options with different parameters are studied. The water manager would buy chooser options in most cases since the system net benefit is increased significantly. Our results show that chooser options are valuable, flexible and low-cost instruments for water resource management. In the future, our model can be further developed in several interesting aspects, including that other complicated exotic option can be designed for water resource management. With development of water market, a proper policy for water option can help managing water shortage risk and reduce the waste of water resource.

\section{Acknowledgements}

This work was supported by Natural Science Foundation of Hebei University (No. 799207217073), the Application Basic Research Plan Key Basic Research Project of Hebei Province (No. 16964213D), Key Laboratory of Machine Learning and Computational Intelligence of Hebei Province (College of Mathematics and Information Science, Hebei University, Baoding 071002, China), National Natural Science Foundation of China (No. 11626079), Natural Science Foundation of Hebei Province (No. F2015402033, No. G2013402063) and Social Science Foundation of Hebei Province (No. HB15GL119).

\section{References}

[1] Li, Y.P. and Huang, G.H. (2008) Interval-Parameter Two-Stage Stochastic Nonlinear Programming for Water Resources Management under Uncertainty. Water Resources Management, 22, 681-698. https://doi.org/10.1007/s11269-007-9186-8

[2] Calatrava, J. and Garrido, A. (2005) Spot Water Markets and Risk in Water Supply. Agricultural Economics, 33, 131-143. https://doi.org/10.1111/j.1574-0864.2005.00402.x

[3] Bjornlund, H. and Rossini, P. (2008) Are the Fundamentals Emerging for More Sophisticated Water Market Instruments? Proceedings from the 14th Annual Conference of the Pacific Rim Real Estate Society, Kuala Lumpur, Malaysia, 1-16.

[4] Burke, S.M., Adams, R.M. and Wallender, W.W. (2004) Water Banks and Environmental Water Demands: Case of the Klamath Project. Water Resources Research, 40.

[5] Cheng, W.C., Hsu, N.S., Cheng, W.M., Yeh, W. and W.-G. (2011) Optimization of European Call Options Considering Physical Delivery Network and Reservoir Operation Rules. Water Resources Research, 47, W10501. https://doi.org/10.1029/2011WR010423

[6] Gómez, A. and Garrido, A. (2004) Formal Risk-Transfer Mechanisms for Allocating Uncertain Water Resources: The Case of Option Contracts. Water Resources Research, 40, W12302. https://doi.org/10.1029/2004WR003340

[7] Hansen, K., Kaplan, J. and Kroll, S. (2014) Valuing Options in Water Markets: A Laboratory Investigation. Environmental and Resource Economics, 57, 59-80. https://doi.org/10.1007/s10640-013-9659-6

[8] Rey, D., Calatrava, J. and Garrido (2016) Optimization of Water Procurement Decisions in an Irrigation District: The Role of Option Contracts. Australian Journal of Agricultural and Resource Economics, 59, 1-25. 
[9] Tomkins, C.D. and Webber, T.A. (2010) Option Contracting in the California Water Market. Journal of Regulatory Economics, 37, 107-141. https://doi.org/10.1007/s11149-009-9107-2

[10] Ha, M. and Gao, Z. (2017) Optimization of Water Allocation Decisions under Uncertainty: The Case of Option Contracts. Journal of Ambient Intelligence \& Humanized Computing, 3, 1-10.

[11] Yamout, G.M., Hatfield, K. and Romeijn, H.E. () Comparison of New Conditional Value-at-Risk-Based Management Models for Optimal Allocation of Uncertain Water Supplies. Water Resources Research, 430, 116-130. https://doi.org/10.1029/2006WR005210

[12] Esogbue, A.O. and Liu, B. (2006) Reservoir Operations Optimization via Fuzzy Criterion Decision Processes. Fuzzy Optimization \& Decision Making, 5, 289-305. https://doi.org/10.1007/s10700-006-0015-y

[13] Stedinger, J.R., Sule, B.F. and Loucks, D.P. (1984) Stochastic Dynamic Programming Models for Reservoir Operation Optimization. Water Resources Management, 20, 1499-1505. https://doi.org/10.1029/WR020i011p01499

[14] Esogbue, A.O., Theologidu, M. and Guo, K. (1992) On the Application of Fuzzy Sets Theory to the Optimal Flood Control Problem Arising in Water Resources Systems. Fuzzy Sets and Systems, 48, 155-172. https://doi.org/10.1016/0165-0114(92)90330-7

[15] Huang, G.H. (1998) A Hybrid Inexact-Stochastic Water Management Model. European Journal of Operational Research, 107, 137-158. https://doi.org/10.1016/S0377-2217(97)00144-6

[16] Hull, J.C. (2012) Options, Futures and Other Derivatives. 8th Edition, Pearson Education Limited, London.

[17] Zhang, P.G. (1998) Exotic Option. World Scientific, Singapore. https://doi.org/10.1142/3800

[18] Cui, J. and Schreider, S. (2009) Modelling of Pricing and Market Impacts for Water Options. Journal of Hydrology, 371, 31-41. https://doi.org/10.1016/j.jhydrol.2009.03.013

[19] Martinkutè-Kaulienè, R. (2012) Exotic Options: A Chooser Option and Its Pricing. Business, Management and Education, 10, 289-301. https://doi.org/10.3846/bme.2012.20

[20] Rubinstein, M. (1991) Exotic Options. Research Program in Finance Working Papers, 229-252.

[21] Ferrero, R.W., Rivera, J.F. and Shahidehpour, S.M. (1998) A Dynamic Programming Two-Stage Algorithm for Long-Terlm Hydrothermal Scheduling of Multireservoir Systems. IEEE Transactions on Power System, 13, 1534-1540. https://doi.org/10.1109/59.736302

[22] Wang, D. and Adams, B.J. (1986) Optimization of Real-Time Reservoir Operations with Markov Decision Processes. Water Resources Research, 22, 345-352. https://doi.org/10.1029/WR022i003p00345

[23] Huang, G.H. and Loucks, D.P. (2000) An Inexact Two-Stage Stochastic Programming Model for Water Resources Management under Uncertainty. Civil Engineering and Environmental Systems, 17, 95-118. https://doi.org/10.1080/02630250008970277

[24] Li, W., Wang, B., Xie, Y.L., Huang, G.H. and Liu, L. (2015) An Inexact Mixed Risk-Aversion Two-Stage Stochastic Programming Model for Water Resources Management under Uncertainty. Environmental Science \& Pollution Research, 22, 
2964-2975. https://doi.org/10.1007/s11356-014-3547-7

[25] Tavakoli, A., Nikoo, M.R., Kerachian, R. and Soltani, M. (2015) River Water Quality Management Considering Agricultural Return Flows: Application of a Nonlinear Two-Stage Stochastic Fuzzy Programming. Environmental Monitoring \& Assessment, 187, 158. https://doi.org/10.1007/s10661-015-4263-6

[26] Xie, Y.L. and Huang, G.H. (2014) Development of an Inexact Two-Stage Stochastic Model with Downside Risk Control for Water Quality Management and Decision Analysis under Uncertainty. Stochastic Environmental Research \& Risk Assessment, 28, 1555-1575. https://doi.org/10.1007/s00477-013-0834-7

[27] Zhou, Y., Huang, G., Wang, S., Zhai, Y. and Xin, X. (2016) Water Resources Management under Dual Uncertainties: A Factorial Fuzzy Two-Stage Stochastic Programming Approach. Stochastic Environmental Research \& Risk Assessment, 30, 795-811. https://doi.org/10.1007/s00477-015-1145-y

[28] Xie, Y.L. and Huang, G.H. (2014) An Optimization Model for Water Resources Allocation Risk Analysis under Uncertainty. Journal of Hydroinformatics, 16, 144-164. https://doi.org/10.2166/hydro.2013.239 